\title{
Group-housed females promote production of asexual ootheca in American cockroaches
}

\author{
Ko Katoh $^{1 *+}$, Masazumi Iwasaki ${ }^{2 \dagger}$, Shouhei Hosono ${ }^{1,5}$, Atsushi Yoritsune ${ }^{2}$, Masanori Ochiai ${ }^{3}$, Makoto Mizunami ${ }^{4}$ \\ and Hiroshi Nishino ${ }^{2^{*}}$
}

\begin{abstract}
Background: Facultative parthenogenesis, seen in many animal phyla, is a reproductive strategy in which females are able to generate offspring when mating partners are unavailable. In some subsocial and eusocial insects, parthenogenesis is often more prevalent than sexual reproduction. However, little is known about how social cooperation is linked to the promotion of parthenogenesis. The domiciliary cockroach Periplaneta americana is well-suited to addressing this issue as this species belongs to the superfamily Blattoidea, which diverged into eusocial termites and shows facultative parthenogenesis.
\end{abstract}

Results: We studied environmental factors that influence asexual production of ootheca using behavioral assays in P. americana. When more than three virgin females immediately after the imaginal molt were kept together in a small sealed container, they tended to produce egg cases (oothecae) via parthenogenesis earlier than did isolated females, resulting in apparent synchronization of ootheca production, even among females housed in different containers. In contrast, virgin females housed with genitalia-ablated males or group-housed females with antennae ablated did not significantly promote ootheca production compared to isolated females. Daily addition of the primary sex pheromone component to the container did not promote ootheca production in isolated females. Another line of study showed that grouped females make parthenogenesis more sustainable than previously known; a founder colony of 15 virgin females was sufficient to produce female progeny for a period of more than three years.

Conclusions: Group-housed females promote and stabilize asexual ootheca production compared to isolated females, and that this promotion is triggered by female-specific chemosensory signals (other than sex pheromone) primarily detected by antennae. Promotion of ootheca production between females is likely to be an early stage of social cooperation, reminiscent of the foundation and maintenance of a colony by female pairs in the eusocial termite Reticulitermes speratus.

Keywords: Cockroaches, Sexual reproduction, Parthenogenesis, group effect, Sex pheromone, Antenna, Chemosensory signal, Periplanone

\section{Background}

Parthenogenesis is a mode of asexual reproduction in which offspring are produced by females without the genetic contribution of a male. This occurs in many animal phyla, from rotifiers, nematodes and arthropods

\footnotetext{
* Correspondence: nishino@es.hokudai.ac.jp; kokatoh@eis.hokudai.ac.jp ${ }^{\dagger}$ Equal contributors

${ }^{1}$ Graduate School of Life Science, Hokkaido University, Sapporo 060-0810, Japan

${ }^{2}$ Research Institute for Electronic Science, Hokkaido University, Sapporo 060-0812, Japan

Full list of author information is available at the end of the article
}

to some lower vertebrates [1-4]. Parthenogenesis results in lower fitness in the long term, because offspring do not generate much genetic diversity [1]. However, in the short term, especially in the presence of abundant resources, parthenogenesis can be a useful strategy for rapidly generating large numbers of female progeny and colonize new habitats, as is known to occur in aphids $[1,4]$.

In most animal groups, parthenogenesis is a strategy secondary to sexual reproduction and occurs only when mating partners (males) are unavailable [1]. Developmental constraints of parthenogens often prevent the evolution of 
parthenogenesis from a sexually reproducing species $[4,5]$. Since most animals that show obligatory parthenogenesis occupy the terminal nodes of phylogenetic trees, the evolutional origin of parthenogenesis could be attributed to the acquisition of a switching mechanism from sexual reproduction to facultative parthenogenesis in more basal taxa [1].

In this context, Blattodea (cockroaches and termites) represent an intriguing phylogenetic group from which sexual reproduction, facultative parthenogenesis and more obligatory parthenogenesis have diversely emerged $[4,6]$. This specific form of parthenogenesis is known as "thelytoky," in which females produce only females from unfertilized eggs [4]. For example, the speckled cockroach Nauphoeta cineria reproduces by facultative parthenogenesis; that is, some are capable of switching from a sexual mode of reproduction to an asexual mode when isolated from males [7, 8]. However, the fitness of parthenogenetically reproducing females is significantly lower than that of sexually reproducing females [8]. In contrast, the Surinam cockroach Pycnoscelus surinamensis exhibits obligatory parthenogenesis; individuals endemic to Indo-Malaysian regions reproduce sexually, but those that were accidentally introduced by humans to other areas such as the USA and Australia reproduce only asexually $[9,10]$. Geographic parthenogenesis is also known in Phyllodromica subaptera, in which asexual forms have spread through most Mediterranean countries, while sexual forms are found only on the Iberian Peninsula [11]. In eusocial termites, Reticulitermes speratus, a female-female colony is formed when kings are not available and is maintained by parthenogenesis [12-14]. Similarly, queen succession in the presence of a king is also maintained by automictic parthenogenesis with terminal fusion [15].

The American cockroach, Periplaneta americana (L.) (Insecta: Blattodea: Blattoidea: Blattidae) is a worldwide pest due to its euryphagous, gregarious behavioral ecologies and close association with human habitats [16]. This species is phylogenetically closer to termites (Blattodea: Blattoidea) than the members of the suborder Blaberoidea, which includes $N$. cineria, $P$. surinamensis and the German cockroach Blattera germanica $[17,18]$. Females of $P$. americana show facultative parthenogenesis in the absence of males $[19,20]$. Although the hatchability of eggs produced by parthenogenesis is lower than that of eggs produced by sexual reproduction [20], the resultant female offspring have been shown to survive through at least two generations in the laboratory [19].

It could be speculated that the ability of females to sense "male-absent conditions" is important in triggering parthenogenesis. However, the decision-making process is not straightforward in group-living animals. Females must be able not only to discriminate other individuals based on sex and kinship [21] but also to evaluate the density and reproductive quality of individuals in populations [5]. There has been no systematic study on how population density affects asexual reproduction in group-living animals (i.e., group effect).

The aim of the present study was to clarify the effect of grouping on asexual ootheca production and to gain insight into sensory cues underlying the promotion of parthenogenesis. Using behavioral assays, we investigated the effects of grouping on asexual ootheca production. Since oothecae delivered to the abdominal tip are soon deposited in P. americana, the precise timing of ootheca production can easily be determined by checking the abdominal tip. Our results show that grouping of females indeed promotes ootheca production, suggesting that this is an early stage of social cooperation, preadaptive to more prevalent parthenogenesis.

\section{Methods \\ Insects}

Adult virgin cockroaches (Periplaneta americana), reared in a 12:12 h light-dark cycle at $28{ }^{\circ} \mathrm{C}$, were used in this study. Laboratory colonies including nymphs and adults of different ages were maintained for approximately four years, during which time wild individuals were added ad libitum to prevent inbreeding. Both males and females were kept separated in the stage of final larval instar to prevent mating and contamination of sex-specific odor. Immediately after the imaginal molt, individuals were used for behavioral observations. Unless otherwise stated, adults with intact genitalia and olfactory organs (pairs of antennae, maxillary palps, and labial palps) were used.

\section{Behavioral assay}

During observation, a cockroach or cockroaches were kept in a sealed circular plastic container $($ diameter $=$ $11 \mathrm{~cm}$; height $=6 \mathrm{~cm}$; volume $=450 \mathrm{~cm}^{3}$, see Fig. 1a). The bottom of the container was lined with a filter paper (Fig. 1a). Minimum aeration was assured by making two small ventilation holes $(\varnothing 2 \mathrm{~mm})$ in the lid. The cockroaches were fed insect food pellets (Oriental Yeast, CO., LTD, Japan) and carrots and given water ad libitum. Individual cockroaches in a single container were marked by trimming forewings to different shapes. Ootheca production was checked visually when a new ootheca was delivered to the tip of the abdomen. In our experimental conditions, we did not observe empty oothecae or resorption of oocytes. We recorded the interval between the imaginal molt and the first ootheca production, and that between the imaginal molt and the second ootheca production. 

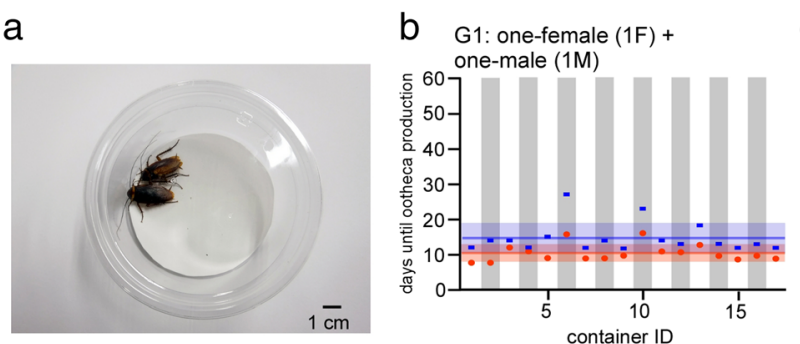

C $\mathrm{G} 2: 1 \mathrm{~F}$

d G3: two-females (2Fs)

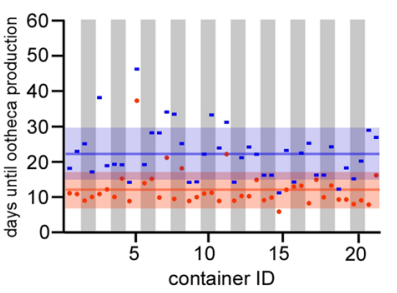

9 G6: $1 \mathrm{~F}+1$ genitalia-

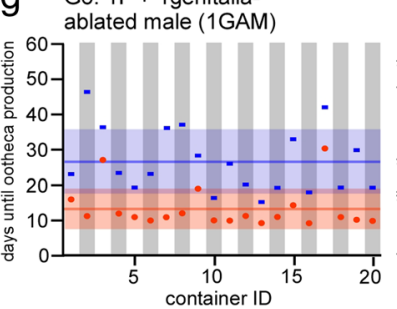

j G9: 3 antennectomized females (AFs)

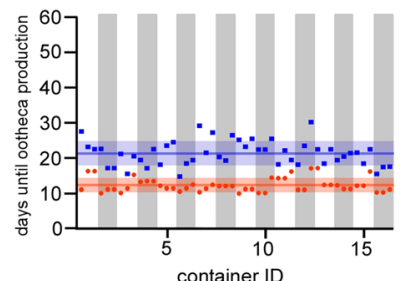

e G4: three-females (3Fs)

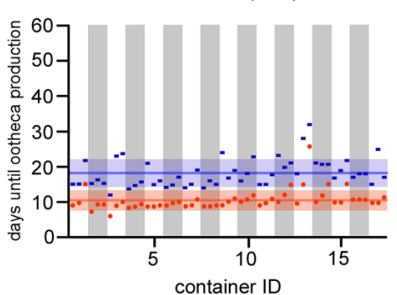

h G7: $1 F+2$ GAMs

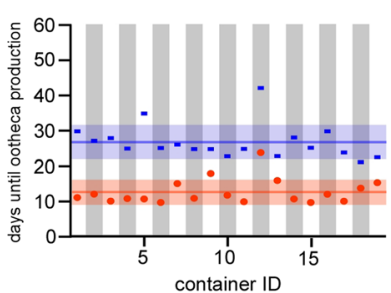

K G10: 3 antennectomized (A) \& palpectomized females (PFs)

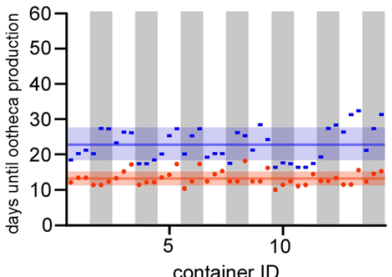

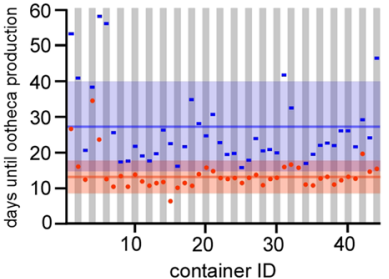

f $\mathrm{G} 5$ : five-females $(5 \mathrm{Fs})$

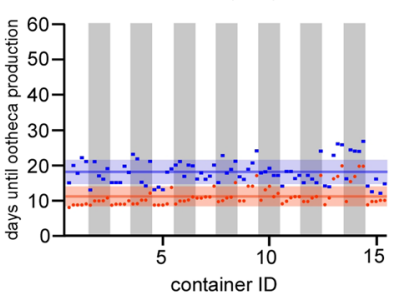

i G8: 3 palpectomized

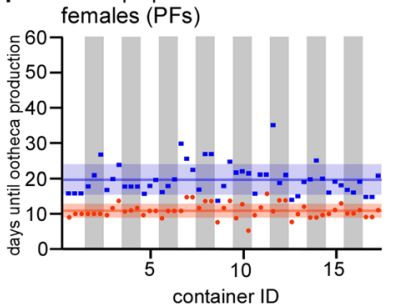

G11: $1 F+$ periplanone-B $(P B)$

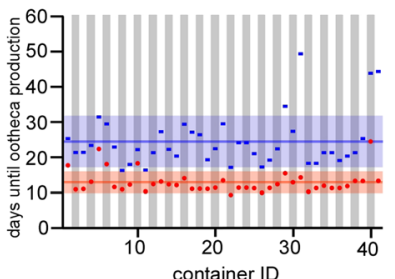

Fig. 1 Timing of the first and second ootheca productions in 11 experimental groups (G1-G11). a Photograph of two female cockroaches housed in a circular plastic container for the behavioral assay. b-I Scatter plots showing intervals between the imaginal molt and the first ootheca production (red) and the second ootheca production (blue) of individual females in different experimental groups. Each dot represents the interval of identified individuals. Red and blue lines indicate the mean period for the first and the second ootheca productions and pale red and blue bands indicate the width of the standard deviation for the first and the second ootheca productions

We conducted 11 sets of behavioral experiments during the same period, from August to 2013 to January 2014 (Table 1). As a control, one female was kept together with one male, permitting sexual reproduction (group 1). Secondly, to evaluate the group-housed effect on asexual reproduction, one female (group 2) was kept in a container and two (group 3), three (group 4) and five females (group 5) were kept together in the container. Thirdly, to assess effects of the presence of males on asexual reproduction, one female was kept with one genitaliaablated male (group 6) or two genitalia-ablated males (group 7). Fourthly, to evaluate possible sensory organs influencing asexual reproduction, three females underwent ablation of maxillary/labial palps (group 8), pairs of antennae (group 9), and all antennae/palps (group 10). Finally, to evaluate the effect of sex pheromones on asexual reproduction, a primary component of sex pheromones, periplanone-B (PB: originally synthesized by Drs. S. Kuwahara and K. Mori and kindly donated by Dr. M. Willis at Case Western Reserve University) [22] was added to a container housing one female (group 11). Periplanone- $\mathrm{B}$ is known to attract distant males and elicit the complete sequence of the male mating display [23].

For surgical ablation of sensory organs, cockroaches were briefly anesthetized by carbon dioxide. Pairs of the entire antennal flagella and palps were excised at their base using microscissors (Vananas Scissors, 500086, WPI). Removal of antennae or palps had little effect on feeding behavior. However, females without antennae and palps tended to be inactive for approximately three 
Table 1 Intervals to the first and second ootheca productions from the imaginal molt in experimental groups

\begin{tabular}{|c|c|c|c|c|c|c|}
\hline Group & Reproduction mode & $\begin{array}{l}\text { 1st ootheca production } \\
\text { (mean } \pm \text { SD) }\end{array}$ & CV & $\begin{array}{l}\text { 2nd ootheca production } \\
\text { (mean } \pm \text { SD) }\end{array}$ & $C V$ & Number \\
\hline One female with one male & sexual & $10.5( \pm 2.5)$ & 0.24 & $14.7( \pm 4.3)$ & 0.29 & 17 \\
\hline One female & asexual & $13.2( \pm 4.7)$ & 0.36 & $27.0( \pm 12.9)$ & 0.48 & 44 \\
\hline Two females & asexual & $11.9( \pm 5.2)$ & 0.44 & $22.0( \pm 7.5)$ & 0.34 & 42 \\
\hline Three females & asexual & $10.4( \pm 2.9)$ & 0.28 & $18.2( \pm 4.0)$ & 0.22 & 51 \\
\hline Five females & asexual & $11.1( \pm 2.9)$ & 0.26 & $18.1( \pm 3.5)$ & 0.19 & 75 \\
\hline One female with one genitalia ablated male & asexual & $13.0( \pm 5.8)$ & 0.44 & $26.3( \pm 9.1)$ & 0.35 & 20 \\
\hline One female with two genitalia ablated males & asexual & $12.6( \pm 3.6)$ & 0.28 & $26.6( \pm 4.9)$ & 0.18 & 19 \\
\hline Three palpectomized females & asexual & $10.9( \pm 2.0)$ & 0.19 & $19.6( \pm 4.3)$ & 0.22 & 51 \\
\hline Three antennectomized females & asexual & $11.9( \pm 2.0)$ & 0.17 & $20.8( \pm 3.5)$ & 0.17 & 48 \\
\hline Three antennae and palpectomised females & asexual & $12.8( \pm 2.0)$ & 0.15 & $22.4( \pm 4.7)$ & 0.21 & 42 \\
\hline One female with periplanone-B & asexual & $12.6( \pm 3.1)$ & 0.25 & $24.1( \pm 7.4)$ & 0.31 & 41 \\
\hline
\end{tabular}

CV coefficient of variation

days before starting to feed. In males, all hooks of the phallomeres of genitalia [24], indispensable for holding the female genitalia in mating, were removed using microscissors (Vananas Scissors, 501778, WPI). We confirmed that the operated males fail to copulate permanently, but other behaviors, such as excretion and courtship behaviors, were unaffected. For sex pheromone application, $1.0 \mathrm{ng}$ synthetic $(-) \mathrm{PB}$, somewhat larger than the daily release of PB $(0.6 \mathrm{ng})$ by one virgin female [25], was dissolved in $10 \mu \mathrm{ln}$-hexane, and a strip of filter paper $(3 \times 10 \mathrm{~mm})$ was immersed in the solution. Immediately after $\mathrm{n}$-hexane had evaporated, the strip was placed on the bottom of a container at the beginning of scotophase. The strip was replaced with a new one each day.

\section{Viability check of asexually and sexually produced oothecae}

To evaluate the viability of eggs produced by parthenogenesis and normal sexual reproduction in our laboratory colony, we collected 33 deposited oothecae from a colony of 20 virgin females and 30 deposited oothecae from a colony containing 10 virgin females and 10 virgin males that were allowed to mate freely. Each ootheca was housed in a $1.5 \mathrm{ml}$ Eppendorf Safe-lock tube with two small holes $(0.5 \mathrm{~mm})$ in the lid for aeration and incubated at $28{ }^{\circ} \mathrm{C}$. The number of eggs hatched from each ootheca was checked visually over a period of two months until all offspring were confirmed to have hatched.

\section{Statistical analysis}

Unless otherwise stated, all values in Results are represented as means \pm SD. The sample size in each group is shown in Table 1. To indicate the extent of variability in relation to the mean of the population, the coefficient of variation $(\mathrm{CV})$ was defined as the ratio of standard deviation to the mean (Table 1). To compare significance of the mean value, analysis of variance (ANOVA) was conducted for all 11 groups. Subsequently, multiple comparisons were made by the Games-Howell test using add-ins attached to Excel (Excel statistics ver. 7.0, Esumi, Japan). Welch's $t$-test was conducted to evaluate hatchability of oothecae, their lengths, and mean number of nymphs per ootheca in sexual and asexual reproductions (Table 2).

\section{Results}

Ootheca production in isolated females (parthenogenesis) and paired female-male (sexual reproduction)

The virgin females isolated immediately after the imaginal molt produced the first ootheca via parthenogenesis at $13.2 \pm 4.7$ days (Figs. 1c and 2a, Table 1), which was not significantly different from that in mated females (10.5 \pm 2.5 days, Figs. $1 \mathrm{~b}$ and 2a, Table 1$)$. However, the second ootheca production was significantly delayed with more variance among individuals $(27.0 \pm 12.9$ days, $\mathrm{CV}=0.48$, Figs. 1c and 2b, Table 1) compared to that in mated females $(14.7 \pm 4.3$ days, $C V=0.29$, Figs. $1 \mathrm{~b}$ and $2 \mathrm{~b})$. These results are generally in good agreement with the results of a previous study [20].

\section{Ootheca production in group-housed females}

When multiple females were kept in the same container, the ootheca production cycle tended to be shortened, with less variance among individuals compared to that in isolated females (Fig. 1d-f, see CVs in Table 1). Apparent synchronization of ootheca production occurred not only in females housed in the same container, but also those housed in different containers (Fig. 1e, f); thus, this is a substantially different phenomenon from menstrual synchrony reported in women living in close proximity [26]. 
Table 2 Viability of sexually and asexually produced oothecae

\begin{tabular}{lllcccc}
\hline & $\begin{array}{l}\text { Total } \\
\text { oothecae }\end{array}$ & $\begin{array}{l}\text { Hatched } \\
\text { oothecae }\end{array}$ & Hatchability (\%) & $\begin{array}{l}\text { lengths of hatched } \\
\text { ootheca }(\mathrm{mm})^{\mathrm{b}}\end{array}$ & $\begin{array}{l}\text { Lengths of unhatched } \\
\text { ootheca }(\mathrm{mm})^{\mathrm{c}}\end{array}$ & $\begin{array}{l}\text { Mean no. of nymphs } \\
\text { per ootheca }( \pm \mathrm{SD})^{\mathrm{d}}\end{array}$ \\
\hline Mated & 30 & 14 & 46.7 & $8.2 \pm 0.8$ & $8.4 \pm 0.6$ & $14.3( \pm 1.5)$ \\
Unmated & 33 & 10 & 30.3 & $8.7 \pm 0.7$ & $8.7 \pm 0.5$ & $9.1( \pm 3.3)^{*}$ \\
\hline
\end{tabular}

Oothecae produced by unmated females were collected from a colony of twenty virgin females. Oothecae were incubated at $28{ }^{\circ} \mathrm{C}$ in a $12: 12 \mathrm{~h}$ light-dark cycle. Welch's $t$-test $P=0.18(>0.05)^{\mathrm{a}}, 0.098(>0.05)^{\mathrm{b}}, 0.156(>0.05)^{\mathrm{c}}, 0.00004(<0.0001)^{\mathrm{d}}$. Asterisk indicates the presence of statistical significance

The shortening and synchronization of the ootheca production cycle became more prominent as the number of housed females increased (Fig. 1d-f, Table 1). For example, the duration until the first ootheca production in three females was significantly shorter than that in isolated females (Fig. 2a, Table 1; 10.4 \pm 2.9 days for the first ootheca production in three females). The durations until the second ootheca production in three females and five females were significantly shorter than that in

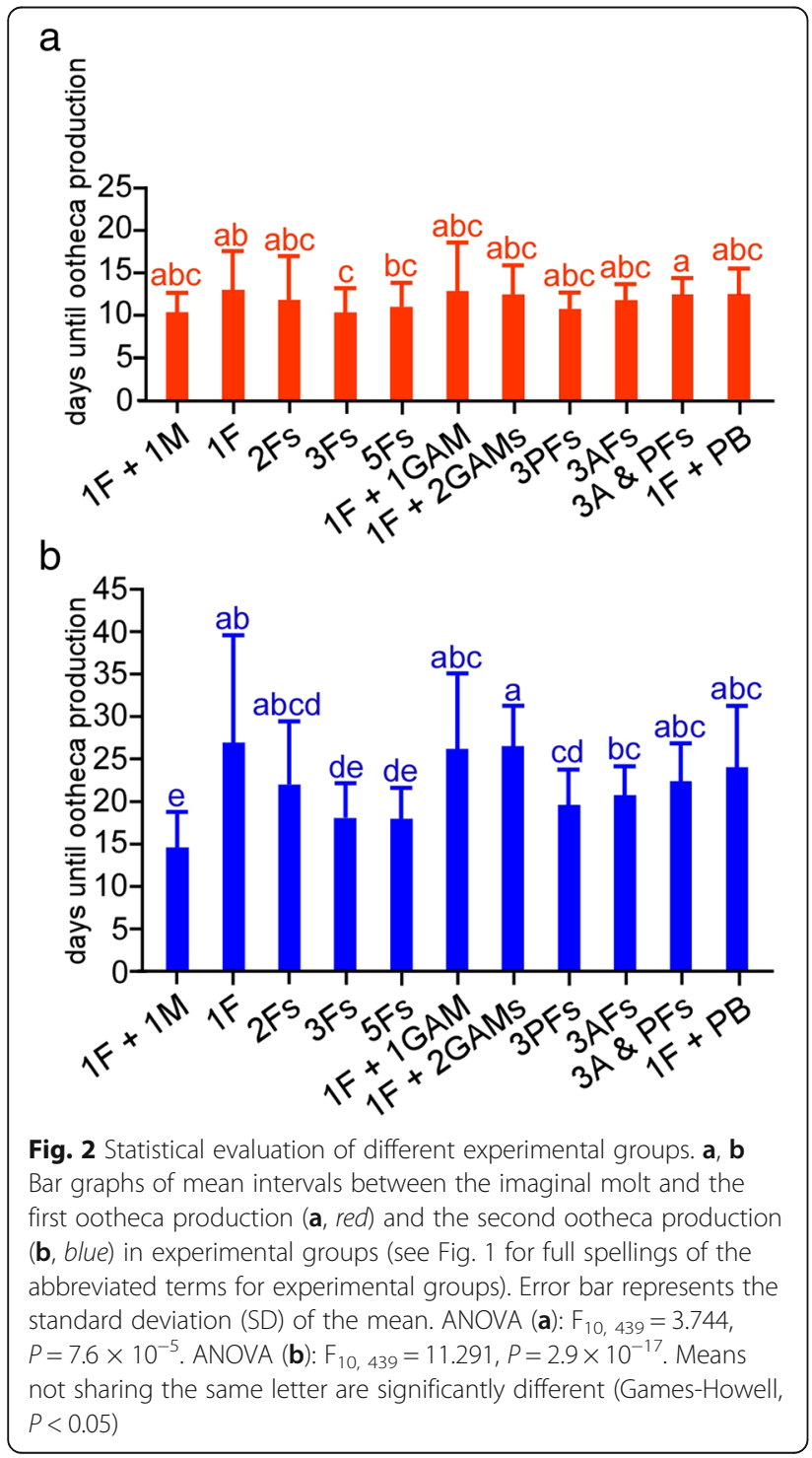

isolated females (Fig. 2b, Table 1; $18.2 \pm 4.0$ for the second ootheca production in three females; $18.1 \pm 3.5$ days for the second ootheca production in five females, Fig. 1f).

\section{Effect of sexual difference of cohabitants on ootheca formation}

To determine the effect of sexual difference of the cohabitants on ootheca production by females, we compared the results when a virgin female was housed with genitalia-ablated males (Fig. 1g, h) to the results when a female was housed with other virgin females (Fig. 1d, e).

When virgin females were paired with genitaliaablated males, the first and second ootheca productions (Fig. 1g, h) were not significantly different from those in isolated females (Fig. 1c), but were delayed compared to those in female-only groups (Fig. 1d, e, Table 1). When a single female was kept with one genitalia-ablated male, the female produced the first ootheca and the second ootheca at $13.0 \pm 5.8$ days and $26.3 \pm 9.1$ days (Figs. $1 \mathrm{~g}$ and 2 , Table 1), respectively, which were delayed, but not significantly compared to cases in which a single female was kept with another female (Figs. 1d and 2, 11.9 \pm 5.2 days for first ootheca production and $22.0 \pm 7.5$ days for second ootheca production). However, when a single female was kept with two genitalia-ablated males, the female produced the second oothecae significantly later (Figs. $1 \mathrm{~h}$ and $2 \mathrm{~b}, 26.6 \pm 4.9$ days) than that when a female was kept with two females (Fig. 1e, $18.2 \pm 4.0$ days).

\section{Sensory organs for discriminating sex of cohabitants}

We evaluated the effect of ablation of primary chemosensory organs (antennae and palps) [16] on ootheca production, because chemosensory signals are known to be important for discrimination of the sex of cohabitants in other cockroach species [27].

Removal of the maxillary/labial palps had little effect on ootheca production in females; the durations to the first and second ootheca production in three females (Figs. 1i and 2a, b, Table 1, $10.9 \pm 2.0$ and $19.6 \pm 4.3$ days, respectively) were not significantly different from those in intact females (Figs. 1e and 2a, b). Antennal removal resulted in a significant delay in the second ootheca productions (Figs. $1 \mathrm{j}$ and $2 \mathrm{~b}$, Table $1,20.8 \pm 3.5$ days) compared to that in intact females (Table 1, Figs. 1e and $2 \mathrm{~b}$ ), suggesting that antennae play a more important role than palps in shortening the duration to ootheca 
production. Moreover, removal of both antennae and maxillary/labial palps resulted in even greater delays in the first ootheca production (Figs. $1 \mathrm{k}$ and 2a, Table 1, $12.8 \pm$ 2.0 days) and second ootheca production (Figs. $1 \mathrm{k}$ and $2 \mathrm{~b}$, Table 1, $22.4 \pm 4.7$ days).

\section{Effect of a sex pheromone on ootheca formation}

Since sex pheromones are emitted by virgin females but much less by mated females in P. americana [25], they may be chemicals that signal a male-absent condition. We therefore investigated whether ootheca production is promoted by daily addition of $1.0 \mathrm{ng} \mathrm{PB}$ to the container housing single females at the beginning of scotophase. However, the results were negative; the durations to first and second ootheca production were not significantly shortened in isolated females exposed to $\mathrm{PB}$ compared to those in isolated females without PB (Fig. 1l, Table 1).

\section{Notes on parthenogenesis in $P$. americana}

Finally, we evaluated how developmental viability differs in sexual reproduction and asexual reproduction. Surprisingly, we found that parthenogenesis in P. americana is more sustainable than previously thought $[19,20]$. We prepared a founder colony of 15 virgin adult females randomly collected from the laboratory colony in December 2013. More than 300 females with differentaged nymphs and adults have survived as of February 2017. Several individuals were photographed immediately after brief anesthetization (Fig. 3). Since the colony has been given food and water ad libitum and kept at an appropriate temperature $\left(28{ }^{\circ} \mathrm{C}\right)$, some individuals may have reached the fifth generation.

The hatchability of oothecae produced by a colony of 20 virgin females was $30.3 \%$ (Table 2), lower than that of

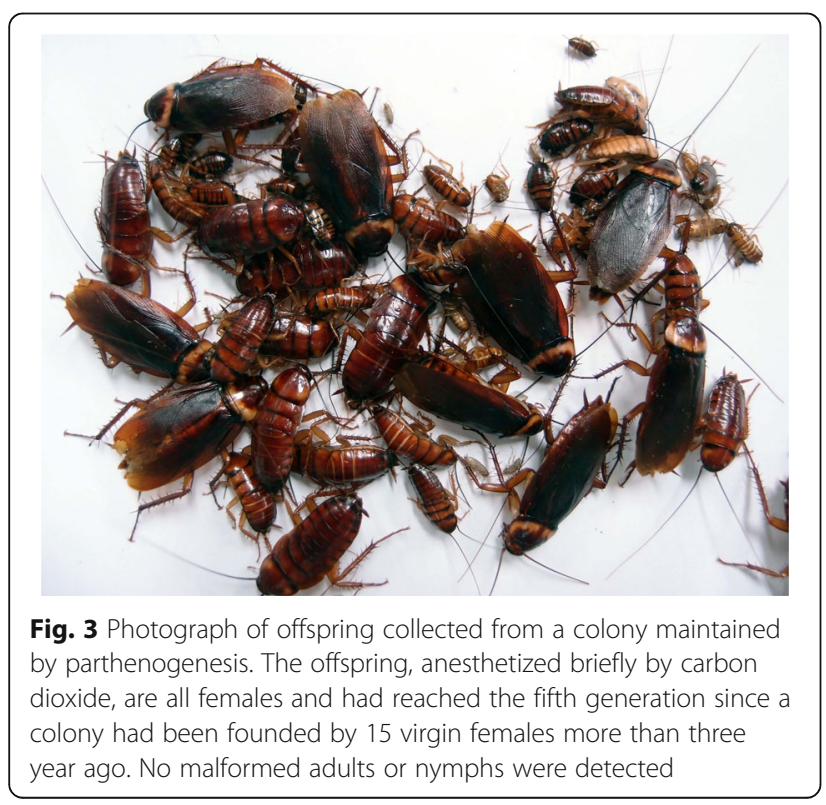

oothecae produced by sexual reproduction (46.7\%, Table 2). The lengths of oothecae produced by asexual reproduction and sexual reproduction were similar, regardless of whether they were hatched or not (Table 2, Additional file 1). The mean numbers of nymphs hatched from each ootheca were significantly smaller for parthenogenesis $(9.1 \pm 3.3)$ than those in sexual reproduction (14.3 \pm 1.5 , Table 2; Additional file 1). These results suggest that parthenogenetic eggs show lower fitness than sexually produced eggs, but the difference is smaller than that in the results of a previous study in which the hatchability of parthenogenetic oothecae was $37.0 \%$, and that of oothecae produced by sexual reproduction was $60.0 \%$ with mean numbers of nymphs hatched from each ootheca being 4.9 for parthenogenesis and 10.8 for sexual reproduction [19].

\section{Discussion}

In group-living animals, grouping of conspecifics decreases mortality rate [28] and promotes nymphal development [28-31], egg production [32], and development of the related endocrine system [32, 33]. These phenomena have been referred to as the "group effect" or "effect of population density".

Our study showed that a group effect is exerted not only on the reproductive mode of females, but also on the parthenogenetic mode of females. In the presence of sufficient resources, the group-housed females after the imaginal molt tended to produce parthenogenetic oothecae earlier and at more similar timings than did isolated females. Since shortening and synchronization of ootheca production cycle occurred not only in those housed in the same container, but also in those kept in different containers, the overall effect of promotion of ootheca production appears to reach a plateau for each individual, resulting in apparent synchronization of ootheca production. This assumption is supported by the finding that the shortening of the ootheca production cycle when five females were grouped was similar to that when three females were grouped. The cycle of parthenogenetic ootheca production is the fastest ever known in this species $[19,20,33]$.

Ootheca production was significantly promoted when females were housed with virgin females but not when they were housed with genitalia-ablated males, suggesting that discrimination of cohabitants' sex is a prerequisite for females to promote ootheca production. Ablation of the largest chemosensory organs, antennae, resulted in a delay in ootheca production compared to that in intact females, although complete ablation of the antennae may have side-effects related to loss of sensory input [34]. Unexpectedly, a typical female-specific odor, the primary sex pheromone component (periplanone-B), did not promote ootheca production, despite the fact that 
the female $P$. americana is equipped with a specific olfactory glomerulus in its first-order olfactory center that processes periplanone- $B[35,36]$.

Given that chemosensory signals are utilized for fine discrimination of the cohabitant status in cockroaches $[21,27]$, we suspect that sensing female-specific odors other than sex pheromones and/or sensing nonvolatile chemicals (e.g., hydrocarbons) [37] via antennal contact with females is most potent for promoting ootheca production. However, our data do not negate the possibility that mechanosensation is involved in the group effect. Although the values were below the significance threshold, some degree of shortening and synchronization of oothecae production occurred in females even without chemosensory organs. Given that tactile stimulation promotes ovary maturation in B. germanica [34, 38], tactile inputs from mechanosensory bristles distributed throughout the body and legs may complementarily promote asexual ootheca production.

On the level of endocrine control, juvenile hormone (JH) III released by the corpus allatum has a pivotal role in promoting the rate of vitellogenic growth and subsequent ootheca production in females [39]. In B. germanica, isolated virgin females have significantly lower rates of JH III synthesis than those in grouped females [40]. Further study is needed to evaluate whether JH III synthesis in P. americana is promoted more in grouphoused females than in isolated females.

What is the functional significance of promotion of asexual ootheca production between females? Shortening of the ootheca production cycle contributes to an increase in parthenogenetic offspring produced by one female. Moreover, synchronizing egg production in grouped females may result in similar hatching timing of their offspring. Nymphs hatched synchronously would increase their fitness by aggregation and by sharing of resources, which could counter the lower hatching rate of parthenogenetic eggs than that of sexually produced eggs $[19,20]$.

In pre-social, domiciliary cockroaches, females of the same kin tend to aggregate in the same colony, whereas males leave the colony to avoid inbreeding [41]. Our behavioral observations are consistent with this finding; unmated females housed in the same container huddle close together with almost no fighting, whereas paired unmated males often fight until the antennae of both individuals are amputated (Nishino, personal observation). Thus, recognition of other virgin females and subsequent promotion of ootheca production might be the early stage of social cooperation that drives more prevalent parthenogenesis. This cooperative behavior is possibly succeeded by eusocial termites, five Reticulitermes species that found the first colony by female-female cooperation $[13,42]$.
As exemplified by $P$. surinamensis and $P$. subaptera, obligatory parthenogenesis very likely arises from facultative parthenogenesis in areas with low population densities. Females are advantageous over males for survival with low population densities. For example, females of $P$. americana, especially unmated ones, live longer than males $[19,43]$. Due to their larger body masses, females are resistant to environmental changes, such as desiccation [9]. Thus, these traits of females appear to be suitable for adapting to new habitats with unfavorable conditions and maintaining female populations via parthenogenesis.

Maintaining certain populations of Periplaneta for more than four generations over a period of three years only by parthenogenesis is a threat to public health because of their potential roles as vectors for pathogens $[44,45]$ and allergens [46] indoors.

The fitness of parthenogens of $P$. americana is estimated to be higher than that of another species that uses facultative parthenogenesis, $N$. cineria, in which the clutch size of asexually produced offspring $(3.2 \pm 2.4)$ is much lower than that of sexually produced offspring $(23.6 \pm 4.2)$ and parthenogized progeny do not survive beyond the third generation [8]. Therefore, care should be taken for the possibility that a female-only colony of $P$. americana may be maintained locally, since benign but spatially isolated conditions can be created in sewage systems in most urban cities. Further investigation is clearly needed to determine whether the sustainability of a female-only colony is due to the inherent nature of wild individuals or to the genetic shift through artificial selection in our laboratory colonies.

One important but yet unsolved issue is whether the automictic parthenogenesis (meiosis and subsequent restoration by the doubling of chromosomes) opted by termites [13] is the case for more basal Blattoidea, $P$. americana. Microsatellite genotyping is needed to understand what kind of reproductive mode contributes to the maintenance of genotypic variance to counter the lower fitness of thelytoky parthenogenesis, and this is probably the key for a deeper understanding of why the genus Periplaneta is so abundant worldwide.

\section{Conclusions}

Group-housed females of the American cockroach $P$. americana promote asexual ootheca production compared to isolated females. A founder colony of 15 virgin females is sufficient to maintain the colony for more than four generations over a period of more than three years only by parthenogenesis. Recognizing femalespecific chemosensory signals via antennae is the most potent sensory cue for promoting ootheca production. The promotion of ootheca production may be an early 
stage of social cooperation linked to more prevalent parthenogenesis adopted by eusocial insects.

\section{Additional file}

Additional file 1: Raw data shown in Table 2. Raw data about lengths of hatched oothecae, lengths of unhatched oothecae and mean numbers of nymphs per hatched oothecae are shown under the Table. $(\mathrm{XLSX} 11 \mathrm{~kb})$

\section{Abbreviations}

$\mathrm{CV}$ : Coefficient of variation; JH: Juvenile hormone; PB: Periplanone-B

\section{Acknowledgments}

The authors are grateful to Dr. M. Soma (Hokkaido University) and K. Terao (Hokkaido University) for advice on statistical analysis and data evaluation and two anonymous reviewers for valuable comments.

\section{Funding}

This work was supported by Grant for Basic Science Research Projects from the Sumitomo Foundation to H.N. (grant number: 120522) and Ministry of Education, Science, Technology, Sports and Culture of Japan; Grant numbers: 23570087 (to H.N) 16H04814; 16 K14774 (to M.M). The funders had no role in the design of the study and collection, analysis, or interpretation of data or in the writing of the manuscript.

\section{Availability of data and materials}

The datasets used and/or analyzed during the current study are available from the corresponding author on reasonable request.

\section{Authors' contributions}

$\mathrm{HN}, \mathrm{Ml}, \mathrm{AY}$ and $\mathrm{KK}$ designed the study. All of the authors wrote the manuscript. $\mathrm{KK}, \mathrm{MI}, \mathrm{SH}, \mathrm{AY}$ and $\mathrm{HN}$ carried out the behavioral experiments. All of the authors read and approved the final manuscript.

\section{Competing interests}

The authors declare that they have no competing interests.

\section{Consent for publication}

Not applicable.

\section{Ethics approval and consent to participate}

Laboratory-maintained insects were used in all experiments. Ethical approval and consent to participate were not required for this work.

\section{Author details}

${ }^{1}$ Graduate School of Life Science, Hokkaido University, Sapporo 060-0810, Japan. ${ }^{2}$ Research Institute for Electronic Science, Hokkaido University, Sapporo 060-0812, Japan. ${ }^{3}$ The Institute of Low Temperature Science, Hokkaido University, Sapporo 060-0819, Japan. ${ }^{4}$ Faculty of Science, Hokkaido University, Sapporo 060-0810, Japan. ${ }^{5}$ Present address: Division of Applied Entomology and Zoology, Graduate School of Agriculture, Tamagawa University, Machida, Tokyo, Japan.

Received: 25 November 2016 Accepted: 22 February 2017 Published online: 13 March 2017

\section{References}

1. Simon JC, Delmotte F, Rispe C, Crease T. Phylogenetic relationships between parthenogens and their sexual relatives: the possible routes to parthenogenesis in animals. Biol J Linn Soc. 2003;79:151-63.

2. Cocco J, Butnariu AR, Bessa E, Pasini A. Sex produces as numerous and long-lived offspring as parthenogenesis in a new parthenogenetic insect. Can J Zool. 2013:91:187-90.

3. Burke NW, Crean AJ, Bonduriansky R. The role of sexual conflict in the evolution of facultative parthenogenesis: a study on the spiny leaf stick insect. Anim Behav. 2015;101:117-27.

4. Vershinina AO, Kuznetsova VG. Parthenogenesis in Hexapoda: Entognatha and non-holometabolous insects. J Zool Syst Evol Res. 2016;54:257-68.
5. Meirmans S, Meirmans PG, Kirkendall LR. The costs of sex: facing real-world complexities. Q Rev Biol. 2012:87:19-40.

6. Bell WJ, Roth LM, Nalepa CA. Cockroaches. Ecology, behavior and natural history. The Johns Hopkins University Press. 2007.

7. Corley LS, Blankenship JR, Moore AJ, Moore PJ. Developmental constraints on the mode of reproduction in the facultatively parthenogenetic cockroach Nauphoeta cinerea. Evol Dev. 1999;1:90-9.

8. Corley LS, Moore AJ. Fitness of alternative modes of reproduction: developmental constraints and the evolutionary maintenance of sex. Proc R Soc B. 1999;266:471-6.

9. Parker EDJ, Niklasson M. Desiccation resistance among clones in the invading parthenogenetic cockroach, Pycnoscelus surinamensis: a search for the general-purpose genotype. J Evol Biol. 1995;8:331-7.

10. Parker EDJ, Selander RK, Hudson RO, Lester LJ. Genetic diversity in colonizing parthenogenetic cockroaches. Evolution. 1977:31:836-42.

11. Knebelsberger T, Bohn H. Geographie parthenogenesis in the subapteragroup of Phyllodromica (Blattoptera, Blattellidae, Ectobiinae). Insect Syst Evol. 2003;34:427-52

12. Matsuura K, Fujimoto M, Goka K, Nishida T. Cooperative colony foundation by termite female pairs: altruism for survivorship in incipient colonies. Anim Behav. 2002;64:167-73.

13. Matsuura K, Fujimoto M, Goka K. Sexual and asexual colony foundation and the mechanism of facultative parthenogenesis in the termite Reticulitermes speratus (Isoptera, Rhinotermitidae). Insect Soc. 2004;51:325-32.

14. Miyazaki S, Yoshimura M, Saiki R, Hayashi Y, Kitade O, Tsuji K, Maekawa K. Intracolonial genetic variation affects reproductive skew and colony productivity during colony foundation in a parthenogenetic termite. BMC Evol Biol. 2014;14:177.

15. Matsuura K, Vargo EL, Kawatsu K, Labadie P, Nakano H, Yahiro T, Tsuji K. Queen succession through asexual reproduction in termites. Science. 2009:323:1687.

16. Gemeno C and Schal C. Sex pheromones of cockroaches. In: Cardé R, Millar J. Advances in insect chemical ecology. Cambridge University Press. 2004. p. 179-259.

17. Pellens R, D'Haese CA, Bellés X, Piulachs MD, Legendre F, Wheeler WC, Grandcolas P. The evolutionary transition from subsocial to eusocial behavior in Dictyoptera: phylogenetic evidence for modification of the "shift-in-dependent-care" hypothesis with a new subsocial cockroach. Mol Phylogenet Evol. 2007:43:616-26.

18. Inward D, Beccaloni G, Eggleton P. Death of an order: a comprehensive molecular phylogenetic study confirms that termites are eusocial cockroaches. Biol Lett. 2007:3:331-5.

19. Roth LM, Willis ER. Parthenogenesis in cockroach. Ann Entomol Soc Am. 1 956:49:195-204

20. Xian X. Effects of mating on oviposition, and possibility of parthenogenesis of three domestic cockroach species, the American cockroach, Periplaneta americana; the smoky brown cockroach, Periplaneta fuliginosa; and the German cockroach, Blattella germanica. Med Entomol Zool. 1998;49:27-32.

21. Lihoreau M, Zimmer C, Rivault C. Kin recognition and incest avoidance in a group-living insect. Behav Ecol. 2007;18:880-7

22. Kuwahara S, Mori K Synthesis of (-)-periplanone-B, a sex pheromone component of the American cockroach. Tetrahedron. 1990;46:8075-82.

23. Seelinger $\mathrm{G}$. Behavioral responses to female sex pheromone components in Periplaneta americana. Anim Behav. 1985;33:591-8.

24. Pipa RL. Muscles and nerves of the posterior abdomen and genitalia of male Periplaneta americana (L.) (Dictyoptera : Blattidae). Int J Insect Morphol Embryol. 1988;17:455-71.

25. Sass H. Production, release and effectiveness of two female sex pheromone components of Periplaneta americana. J Comp Physiol A. 1983;152:309-17.

26. McClintock MK. Menstrual synchrony and suppression. Nature. 1971;229:244-5.

27. Moore AJ. Female preferences, male social status, and sexual selection in Nauphoeta cinerea. Anim Behav. 1988:36:303-5.

28. Wharton DR, Lola JE, Wharton ML. Population density, survival, growth, and development of the American cockroach. J Insect Physiol. 1967;13:699-716.

29. Wharton DR, Lola JE, Wharton ML. Growth factors and population density in the American cockroach, Periplaneta americana. J Insect Physiol. 1968:14:637-53.

30. Izutsu M, Ueda S, Ishii S. Aggregation effects on the growth of the German cockroach Blattella germanica (L.) (Blattaria: Blattellidae). Appl Entomol Zool. 1970;5:159-71

31. Katvala M, Kaitala A. The effect of conspecific density on female reproduction in an egg-carrying bug. Anim Behav. 2005;69:269-73. 
32. Uzsák A, Schal C. Differential physiological responses of the German cockroach to social interactions during the ovarian cycle. J Exp Biol. 2012;215:3037-44.

33. Weaver RJ, Pratt GE. The effect of enforced virginity and subsequent mating on the activity of the corpus allatum of Periplaneta americana measured in vitro, as related to changes in the rate of ovarian maturation. Physiol Entomol. 1977;2:59-76.

34. Uzsák A, Schal C. Sensory cues involved in social facilitation of reproduction in Blattella germanica females. PLoS One. 2013;8:e55678.

35. Nishino $H$, Yoritsune A, Mizunami M. Postembryonic development of sexually dimorphic glomeruli and related interneurons in the cockroach Periplaneta americana. Neurosci Lett. 2010;469:60-4.

36. Nishino H, Iwasaki M, Mizunami M. Pheromone detection by a pheromone emitter: a small sex pheromone-specific processing system in the female American cockroach. Chem Senses. 2011:36:261-70.

37. Lihoreau M, Rivault C. Kin recognition via cuticular hydrocarbons shapes cockroach social life. Behav Ecol. 2009;20:46-53.

38. Lihoreau M, Rivault C. Tactile stimuli trigger group effect in cockroach aggregations. Anim Behav. 2008;75:1965-72.

39. Marchal E, Hult EF, Huang J, Stay B, Tobe SS. Diploptera punctata as a model for studying the endocrinology of arthropod reproduction and development. Gen Comp Endocrinol. 2013;188:85-93.

40. Gadot M, Burns E, Schal C. Juvenile hormone biosynthesis and oocyte development in adult female Blattella germanica: effect of grouping and mating. Arch Insect Biochem Physiol. 1989;11:189-200.

41. Lihoreau M, Costa JT, Rivault C. The social biology of domiciliary cockroaches: colony structure, kin recognition and collective decisions. Insect Soc. 2012;59:445-52.

42. Kawatsu K, Matsuura K. Preadaptation for parthenogenetic colony foundation in subterranean termites Reticulitermes spp. (Isoptera: Rhinotermitidae). J Ethol. 2013;31:123-8.

43. Griffiths JT, Tauber OE. Fecundity, longevity, and parthenogenesis of the American roach, Periplaneta americana L. Physiol Zool. 1942;15:196-209.

44. Devi SJ, Murray CJ. Cockroaches (Blatta and Periplaneta species) as reservoirs of drug-resistant salmonellas. Epidemiol Infect. 1991;107:357-61.

45. Fakoorziba MR, Eghbal F, Hassanzadeh J, Moemenbellah-Fard MD. Cockroaches (Periplaneta americana and Blattella germanica) as potential vectors of the pathogenic bacteria found in nosocomial infections. Ann Trop Med Parasitol. 2010;104:521-8.

46. Fang $Y$, Long C, Bai X, Liu W, Rong M, Lai R, An S. Two new types of allergens from the cockroach, Periplaneta americana. Allergy. 2015;70:1674-8.

\section{Submit your next manuscript to BioMed Central and we will help you at every step:}

- We accept pre-submission inquiries

- Our selector tool helps you to find the most relevant journal

- We provide round the clock customer support

- Convenient online submission

- Thorough peer review

- Inclusion in PubMed and all major indexing services

- Maximum visibility for your research

Submit your manuscript at www.biomedcentral.com/submit

) Biomed Central 